\title{
Effect of Copper on 1,1-Diamino-2,2-dinitroethene - A DFT Treatment
}

\section{Lemi Türker}

Department of Chemistry, Middle East Technical University, Üniversiteler, Eskişehir Yolu No: 1, 06800 Çankaya/Ankara, Turkey; e-mail: 1turker@gmail.com; lturker@metu.edu.tr

\begin{abstract}
Interaction of 1,1-diamino-2,2-dinitroethene which is a well known explosive called FOX-7 and copper atom is investigated computationally in the form of 1:1 composite, at the levels of UB3LYP/6-31++G(d,p) and UB3LYP/LANL2DZ within the restrictions of density functional theory. Some geometrical, spectral and quantum chemical data have been obtained and discussed. The both levels of computational approach yield geometries in accord with each other but LANL2DZ basis set produced unreasonable charges for the atoms of the composite. However, both of the methods indicate that copper atom donates some electron population to the organic component meantime the nitro groups change their conformation by twisting about the $\mathrm{C}-\mathrm{NO}_{2}$ bonds. Thus, the push-pull character of the system varies which should affect some of the explosive properties, beside the others.
\end{abstract}

\section{Introduction}

1,1-Diamino-2,2-dinitroethene $\left(\mathrm{C}_{2} \mathrm{H}_{4} \mathrm{~N}_{4} \mathrm{O}_{4}\right)$, geminal DADNE, also known as FOX-7 (preferred name in the present study) is commonly expected to be a promising explosive, combining comparatively high performance and low sensitivity. It has a push-pull type structure which is beneficial for the creation of strong inter- and intra-molecular hydrogen bonds for stabilizing the molecule. Since 1998, when FOX-7 was first synthesized by Latypov et al. [1], it has been the subject of many experimental investigations [2-15]. FOX-7 has a favorable oxygen balance and its decomposition produces some gaseous products $\left(\mathrm{CO}, \mathrm{H}_{2} \mathrm{O}, \mathrm{N}_{2}\right)$. Also it is far less sensitive to impact

Received: August 14, 2020; Accepted: September 17, 2020

Keywords and phrases: DADNE, FOX-7, copper, explosive, density functional.

Copyright (C) 2021 Lemi Türker. This is an open access article distributed under the Creative Commons Attribution License, which permits unrestricted use, distribution, and reproduction in any medium, provided the original work is properly cited. 
and shock than $\mathrm{RDX}$ (1,3,5-trinitro-1,3,5-triazinane), but its explosive properties are comparable to those of RDX. For these reasons FOX-7 has been accepted as very useful for systems in which insensitivity is more important than maximum performance [16]. A review by Bellamy includes routes for the synthesis of FOX-7, together with its structural, spectroscopic, and explosive properties [17]. Kretschmer et al. investigated the chemical stability, sensitivity and mechanical and explosive properties of mixtures of FOX-7 with paraffin, ethylene-propylene rubber (EPM) and the polyacrylate elastomer (Hy Temp) [18]. Interactions of FOX-7 with various elements are found in the literature [19-21].

In the present study, interaction of copper with FOX-7 structure has been investigated quantum chemically in the realm of density functional theory (DFT).

\section{Method of Calculation}

In the present study, the initial structural optimizations of all the structures leading to energy minima have been achieved by using MM2 method followed by semi-empirical PM3 self-consistent fields molecular orbital (SCF MO) method [22, 23] at the restricted level $[24,25]$. Subsequent optimizations were achieved at Hartree-Fock level using various basis sets. Then, the structural optimizations were managed within the framework of density functional theory (DFT) $[26,27]$ at the levels of UB3LYP/6$31++\mathrm{G}(\mathrm{d}, \mathrm{p})[25,28]$ and UB3LYP/LANL2DZ [29] both of which are suitable for copper atom. Note that in the ground state copper atom possesses an unpaired electron thus the calculations have been performed employing the unrestricted methodology. The exchange term of B3LYP consists of hybrid Hartree-Fock and local spin density (LSD) exchange functions with Becke's gradient correlation to LSD exchange [27, 30]. The correlation term of B3LYP consists of the Vosko, Wilk, Nusair (VWN3) local correlation functional [31] and Lee, Yang, Parr (LYP) correlation correction functional [32]. Also, the vibrational analyses have been done. The total electronic energies are corrected for the zero point vibrational energy (ZPE). The normal mode analysis for each structure yielded no imaginary frequencies for the $3 \mathrm{~N}-6$ vibrational degrees of freedom, where $N$ is the number of atoms in the system. This indicates that the structure of each molecule corresponds to at least a local minimum on the potential energy surface. All these calculations were done by using the Spartan 06 package program [33]. 


\section{Results and Discussion}

Copper in the field of explosives emerges mainly in the structures of primary explosives as copper salts of certain explosives, such as azides [34]. It has some subsidiary applications in the ammunition compositions or in the construction of shaped charge devices [35]. Interaction of it with explosives, at least with FOX-7 has not been studied yet up to the best knowledge of the author.

In the ground state, copper has $[\mathrm{Ar}] 3 \mathrm{~d}^{10} 4 \mathrm{~s}^{1}$ electronic configuration. Copper interacts with ammonia to some extent $[36,37]$.

FOX-7 being a push-pull type structure, the electron density on the amino nitrogens is expected to be low in contrast to density on oxygen atoms of $\mathrm{NO}_{2}$ groups.
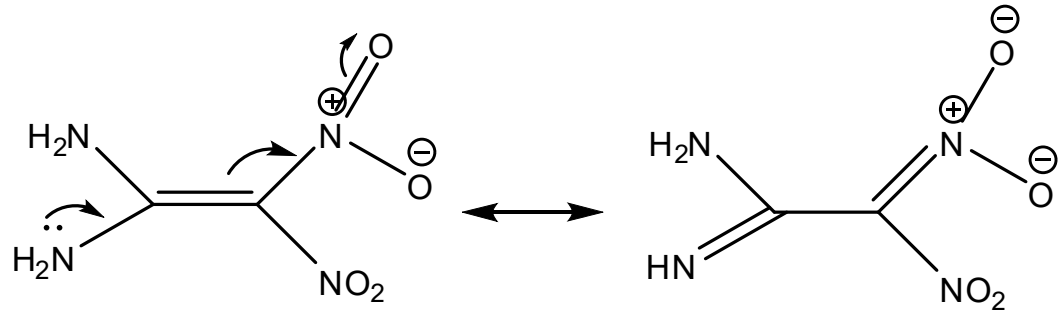

Therefore, more than one site happens to undergo interactions with copper atom, with its empty atomic orbitals or its unshared electron in attractive or repulsive manner.

Figure 1 shows the optimized structures of FOX-7 and the composite considered. It also shows the direction of the dipole moment vectors. FOX-7 molecule is nearly coplanar at the amino side but has inclined at the nitro side having $\mathrm{N} 2 \mathrm{C} 2 \mathrm{C} 1 \mathrm{~N} 4$ and $\mathrm{N} 1 \mathrm{C} 2 \mathrm{C} 1 \mathrm{~N} 3$ dihedral angles of $13.16^{\circ}$ and $13.19^{\circ}$ (see Figure 2 for numbering of the atoms). The same angles in the composite have the values of $2.72^{\circ}$ and $5.70^{\circ}$. The $\mathrm{O} 4 \mathrm{~N} 4 \mathrm{C} 1 \mathrm{C} 2$ and $\mathrm{O} 2 \mathrm{~N} 3 \mathrm{C} 1 \mathrm{C} 2$ dihedral angles are in FOX-7 are $-23.15^{\circ}$ and $154.93^{\circ}$, whereas in the composite $-42.57^{\circ}$ and $174.52^{\circ}$, respectively.

The $\mathrm{NH}_{2}-\mathrm{C}$ bond lengths in FOX-7 are $1.34 \AA$ whereas in the composite $1.35 \AA$ and $1.34 \AA$. The $\mathrm{C}=\mathrm{C}$ bond in FOX-7 is $1.42 \AA$ but in the composite it is $1.41 \AA$. The $\mathrm{C}-\mathrm{NO}_{2}$ bond lengths in FOX-7 are $1.43 \AA$ but in the composite $1.40 \AA$. Therefore the presence of copper atom slightly affects the bond lengths. 

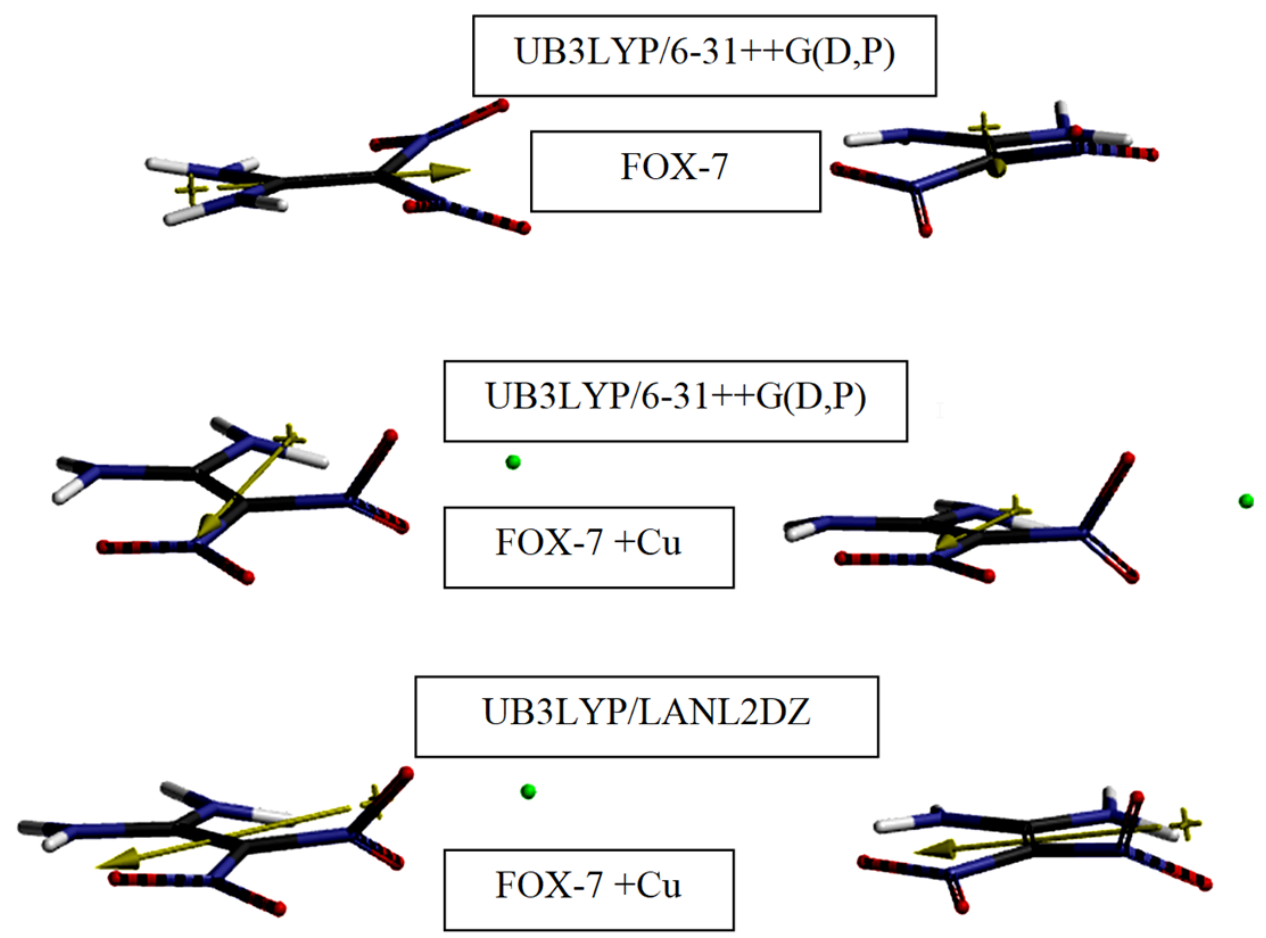

Figure 1. Optimized structures of FOX-7 and the composite considered (from different angles of view).
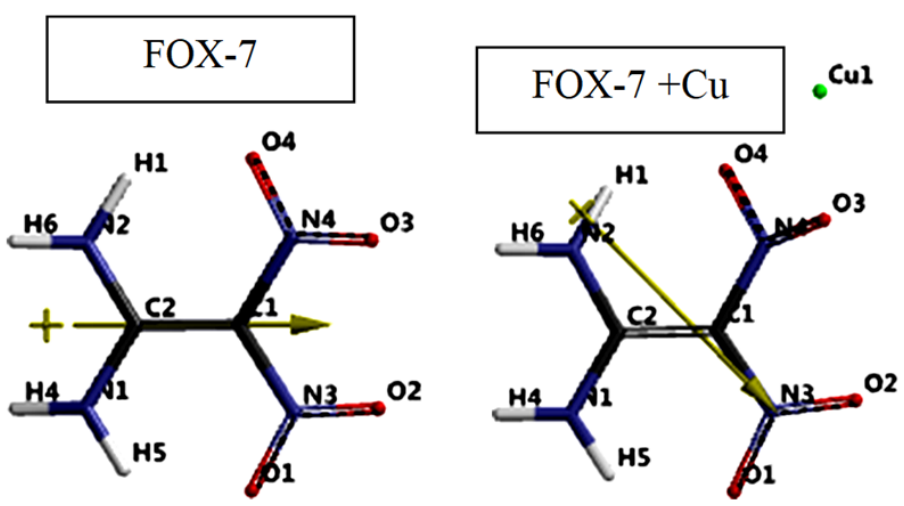

Figure 2. Numbering of the atoms in the structures considered.

Figure 3 shows the electrostatic charges (ESP) on the atoms of FOX-7 and its copper composite. Note that the ESP charges are obtained by the program based on a numerical method that generates charges that reproduce the electrostatic potential field from the entire wavefunction [33]. 

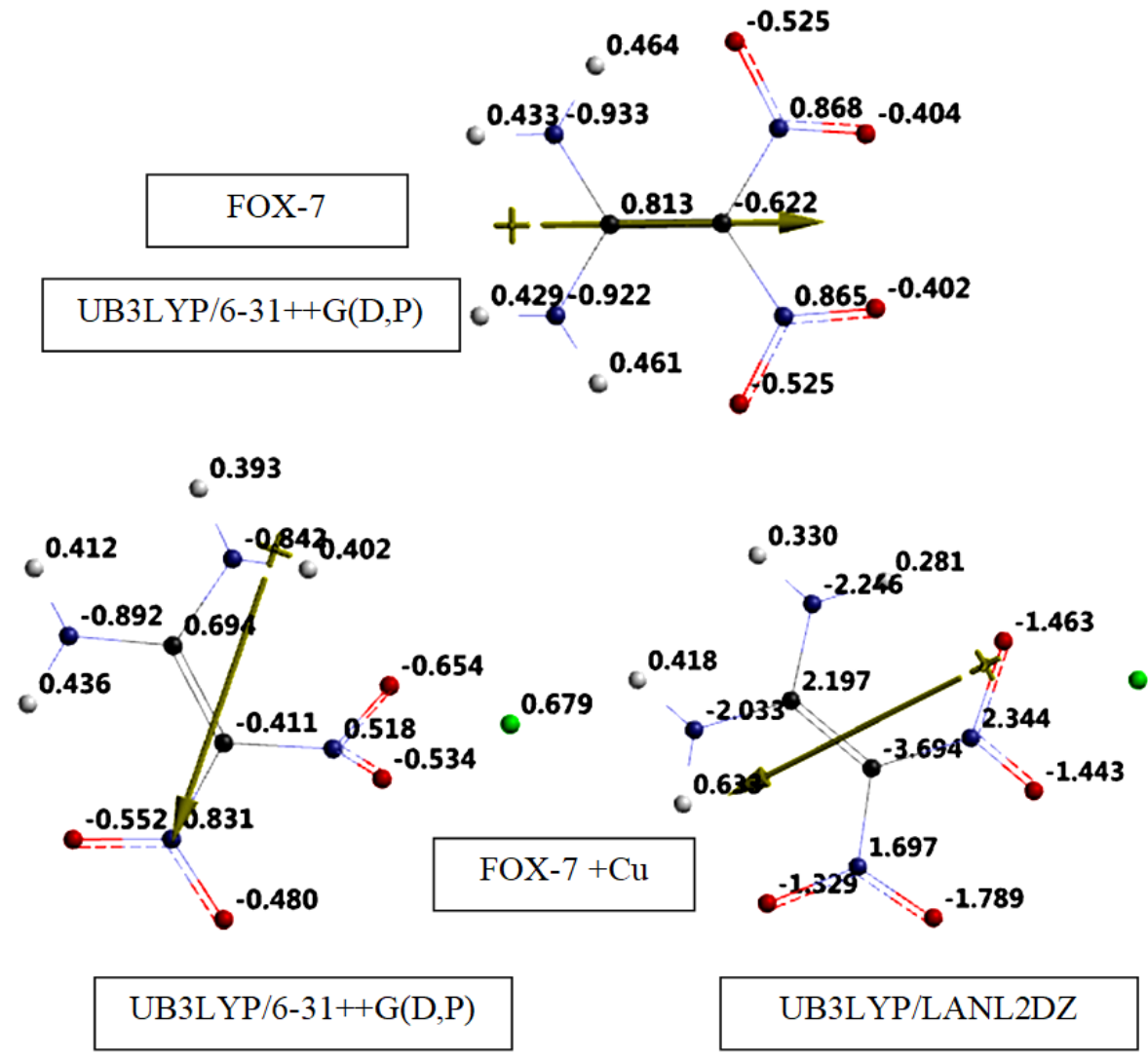

Figure 3. ESP charges on the atoms of FOX-7 and the composite considered.

The UB3LYP/LANL2DZ level of calculation predicts rather unreasonable positive charge development on the copper atom in the composite, so do the charges on the other atoms. The UB3LYP/6-31++G(d,p) level of calculation yields a reasonable positive charge for the copper atom. By comparing the magnitudes of charges on FOX-7 and the composite, one observes that the copper atom transfers some electron population into the organic component so that less amount of charges (absolutely) emerge on the carbon atoms, thus push-pull character of the system is highly affected. The positive charge on $\mathrm{N} 4$ has been decreased compared to the charge of the respective atom in FOX-7 whereas the negative charges on $\mathrm{O} 3$ and $\mathrm{O} 4$ are increased. The dipole moment values (UB3LYP/6-31++G(D,P)) are 8.68 and 8.40 debye, respectively for FOX-7 and FOX$7+\mathrm{Cu}$. The UB3LYP/LANL2DZ level of calculation on the composite yields the dipole moment as 60.86 debye. One should observe the direction of the dipole moment vectors in the composite case by the two methods of calculations performed. 
Figure 4 shows the IR spectra of the species considered (UB3LYP/6-31++G(d,p)). The presence of copper atom affects $\mathrm{N}-\mathrm{H}$ stretching and bending frequencies as well as $\mathrm{C}=\mathrm{C}$ and $\mathrm{C}-\mathrm{NO}_{2}$ stretchings. Symmetric and asymmetrical N-H stretchings in FOX-7 occur at $3468 \mathrm{~cm}^{-1}$ and $3693 \mathrm{~cm}^{-1}$, respectively. Whereas in the composite they are at $3422 \mathrm{~cm}^{-1}$ and $3694 \mathrm{~cm}^{-1}$, respectively. The $\mathrm{NH}_{2}$ scissoring of FOX-7 occurs at $1645 \mathrm{~cm}^{-1}$ whereas at $1663 \mathrm{~cm}^{-1}$ in the composite. The $\mathrm{C}-\mathrm{NH}_{2}$ and $\mathrm{C}-\mathrm{NO}_{2}$ stretchings strongly appear in the case of the composite in the range of $1569-1324 \mathrm{~cm}^{-1}$.
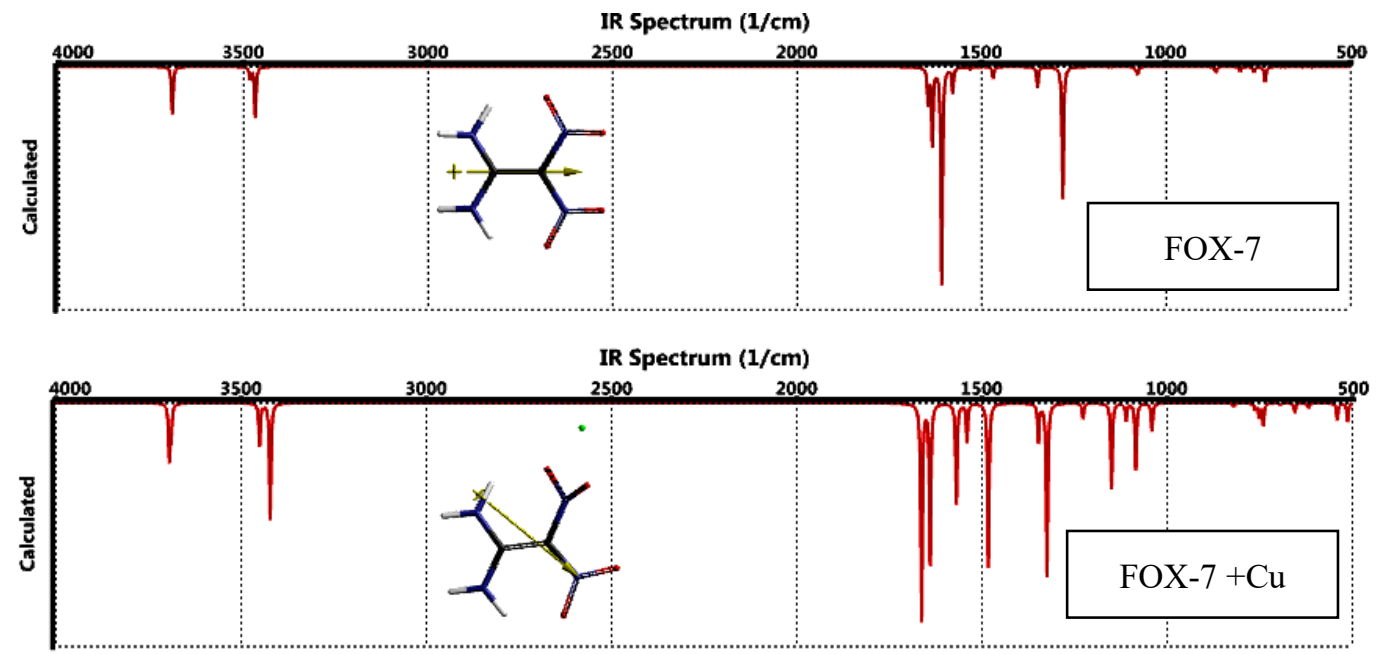

Figure 4. IR spectra of the structures considered (UB3LYP/6-31++G(d,p)).

Figure 5 displays the electrostatic potential maps of FOX-7 and its copper composite
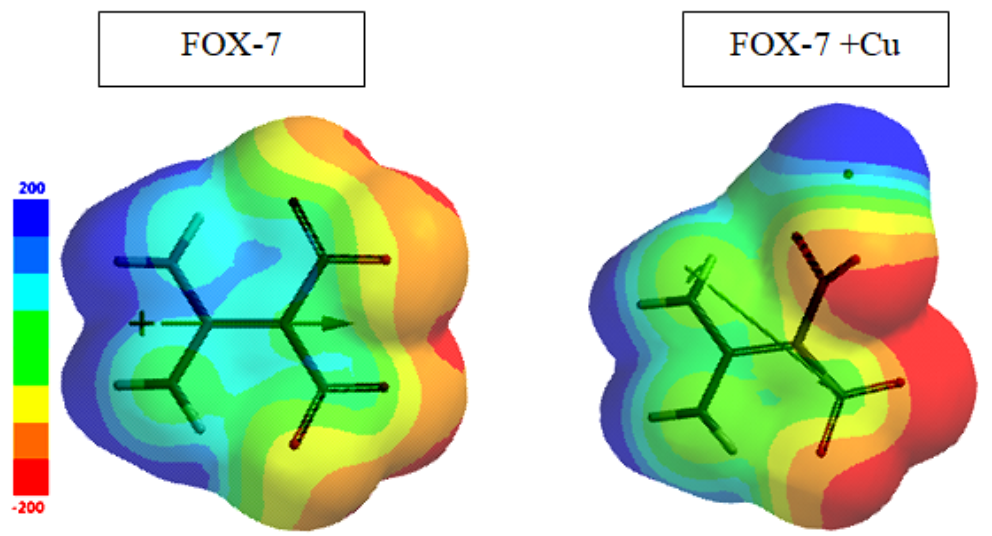

Figure 5. Electrostatic potential maps of the structures considered (UB3LYP/6$31++G(D, P))$. 
(UB3LYP/6-31++G(d,p)). In the figure red/reddish and blue/ green regions stand for negative and positive potential fields, respectively. The presence of copper atom enhances the negative potential around the $\mathrm{NO}_{2}$ oxygens as compared to FOX-7 case while decreasing the positive potential around the $\mathrm{NH}_{2}$ groups. A very pronounced positive potential field exists around the copper atom.

Table 1 shows the HOMO, LUMO energies and the interfrontier molecular orbital energy gap $(\Delta \varepsilon)$ values of the structures considered. As seen in the table the incorporation of copper atom in the structure raises up the HOMO and LUMO energy levels of FOX-7. This is usually the case whenever some electron donating group(s) linked to the conjugated system. In the present case the copper atom takes the role of electron donor group. These changes affect the $\Delta \varepsilon$ values in the order of FOX-7 > FOX $-7+\mathrm{Cu}$. Since $\Delta \varepsilon$ value of an explosive is associated with its sensitivity to impact $[38,39]$, such that as $\Delta \varepsilon$ decreases the impact sensitivity increases, the copper composite of FOX-7 is expected to be more sensitive than the parent explosive. Structurally, $\mathrm{NH}_{2}$ groups (electron donors) in FOX-7 raise up the HOMO and LUMO energy levels as compared to ethylene case whereas the nitro groups (electron acceptors) lower those energy levels $[40,41]$. Normally, twistings of the $\mathrm{NO}_{2}$ groups about the $\mathrm{C}-\mathrm{NO}_{2}$ bonds decrease the extended conjugation thus those energy levels are expected to be raised in the composite. However, donation of some electron population from the copper atom, in which case it takes the role of an electron donor group, raises up the energies of the frontier molecular orbitals to yield the values shown in Table 1.

Table 1. The HOMO, LUMO energies and $\Delta \varepsilon$ values of the structures considered.

\begin{tabular}{lccc}
\hline Structure & HOMO & LUMO & $\Delta \varepsilon$ \\
\hline FOX-7 & -722.34 & -276.03 & 446.31 \\
FOX-7 $+\mathrm{Cu}$ & -506.97 & -271.66 & 235.31 \\
\hline
\end{tabular}

Energies in $\mathrm{kJ} / \mathrm{mol}$. UB3LYP/6-31++G(d,p) level of calculations.

Tables 2 and 3 show the Mulliken bond orders and lengths in FOX-7 and the composite both calculated at the UB3LYP/6-31++G(d,p) level whereas Table 4 contains Löwdin bond orders and lengths of the composite. 
Table 2. Mulliken bond orders of FOX-7.

\begin{tabular}{cccc}
\hline Bond & Bond order & Length $(\AA)$ & Remark \\
\hline C1 C2 & 1.404 & 1.4279 & [deloc] \\
C1 N3 & 0.790 & 1.4319 & [single] \\
C1 N4 & 0.789 & 1.4322 & [single] \\
C2 N1 & 1.310 & 1.345 & [deloc] \\
C2 N2 & 1.309 & 1.3451 & [deloc] \\
N1 H4 & 0.824 & 1.0083 & [sing-H] \\
N1 H5 & 0.727 & 1.0173 & [sing-H] \\
H5 O1 & 0.081 & 1.8074 & [Hbond] \\
N2 H1 & 0.727 & 1.0171 & [sing-H] \\
N2 H6 & 0.824 & 1.0083 & [sing-H] \\
H1 O4 & 0.081 & 1.8069 & [Hbond] \\
N3 O1 & 1.807 & 1.2573 & [double] \\
N3 O2 & 2.145 & 1.2252 & [double] \\
N4 O3 & 2.144 & 1.2252 & [double] \\
N4 O4 & 1.807 & 1.2571 & [double] \\
\hline
\end{tabular}

UB3LYP/6-31++G(d,p) level of calculations. Refer Figure 2 for numbering of the atoms.

Comparison of the data in the tables indicates some changes in the bond orders and bond lengths. The data in Table 4 shows that some interactions, almost equal, take place between the copper atom and the nearby oxygen atoms of the $\mathrm{NO}_{2}$ group. 
Table 3. Mulliken bond orders of the composite.

\begin{tabular}{cccc}
\hline Bond & Bond order & Length $(\AA)$ & Remark \\
\hline C1 C2 & 1.435 & 1.4104 & [deloc] \\
C1 N3 & 0.905 & 1.4041 & [single] \\
C1 N4 & 0.525 & 1.4054 & [single] \\
C2 N1 & 1.281 & 1.3464 & [deloc] \\
C2 N2 & 1.270 & 1.3541 & [deloc] \\
N1 H4 & 0.822 & 1.008 & [sing-H] \\
N1 H5 & 0.725 & 1.0192 & [sing-H] \\
H5 O1 & 0.084 & 1.8373 & [Hbond] \\
N2 H1 & 0.742 & 1.0203 & [sing-H] \\
N2 H6 & 0.815 & 1.0077 & [sing-H] \\
H1 O4 & 0.102 & 1.8582 & [Hbond] \\
N3 O1 & 1.818 & 1.2645 & [double] \\
N3 O2 & 2.149 & 1.2355 & [double] \\
N4 O3 & 1.396 & 1.3225 & [deloc] \\
N4 O4 & 0.982 & 1.3501 & [single] \\
N4 Cu & 1.127 & 2.3144 & [single] \\
\hline
\end{tabular}

UB3LYP/6-31++G(d,p) level of calculations. Refer Figure 2 for numbering of the atoms.

Table 3 shows the Löwdin bond orders and lengths in the composite. 
Table 4. Löwdin bond orders of the composite.

\begin{tabular}{|c|c|c|c|c|}
\hline \multicolumn{2}{|c|}{ Bond } & \multirow{2}{*}{$\frac{\text { Bond order }}{1.236}$} & \multirow{2}{*}{$\frac{\text { Length }(\AA)}{1.4104}$} & \multirow{2}{*}{$\frac{\text { Remark }}{[\text { single }]}$} \\
\hline $\mathrm{C} 1$ & $\mathrm{C} 2$ & & & \\
\hline $\mathrm{C} 1$ & N3 & 1.135 & 1.4041 & [single] \\
\hline $\mathrm{C} 1$ & N4 & 1.075 & 1.4054 & [single] \\
\hline $\mathrm{C} 2$ & N1 & 1.442 & 1.3464 & [deloc] \\
\hline $\mathrm{C} 2$ & $\mathrm{H} 4$ & 0.052 & 2.0516 & [Hbond] \\
\hline $\mathrm{C} 2$ & $\mathrm{~N} 2$ & 1.407 & 1.3541 & [deloc] \\
\hline N1 & H4 & 0.891 & 1.008 & [sing-H] \\
\hline N1 & H5 & 0.833 & 1.0192 & [sing-H] \\
\hline H5 & $\mathrm{O} 1$ & 0.087 & 1.8373 & [Hbond] \\
\hline $\mathrm{N} 2$ & $\mathrm{H} 1$ & 0.835 & 1.0203 & [sing-H] \\
\hline $\mathrm{N} 2$ & H6 & 0.896 & 1.0077 & [sing-H] \\
\hline H1 & $\mathrm{O} 4$ & 0.079 & 1.8582 & [Hbond] \\
\hline N3 & $\mathrm{O} 1$ & 1.797 & 1.2645 & [double] \\
\hline N3 & $\mathrm{O} 2$ & 1.924 & 1.2355 & [double] \\
\hline N4 & $\mathrm{O} 3$ & 1.529 & 1.3225 & [deloc] \\
\hline N4 & $\mathrm{O} 4$ & 1.436 & 1.3501 & [deloc] \\
\hline $\mathrm{O} 3$ & $\mathrm{Cu}$ & 0.551 & 1.9529 & [single] \\
\hline $\mathrm{O} 4$ & $\mathrm{Cu}$ & 0.545 & 1.9713 & [single \\
\hline
\end{tabular}

UB3LYP/6-31++G(d,p) level of calculations. Refer Figure 2 for numbering of the atoms.

Figure 6 shows some of the molecular orbital energies of FOX-7 and the composite. Since copper atom has an unpaired electron in its ground electronic state, the composite has $\alpha$ - and $\beta$-orbitals. In the figure those orbitals are designated as a- and b-orbitals. As seen in the figure UB3LYP/6-31++G(D,P) level of calculations yield almost nearly degenerate $\alpha$ - and $\beta$-HOMOs (also LUMO energy levels) for the composite. As for the 
UB3LYP/LANL2DZ level of calculations, the frontier molecular orbital energy levels are to be noticed that they have positive energy values and the HOMO-LUMO energy differences (either $\alpha$ - or $\beta$-type) are about $1 \mathrm{eV}$.
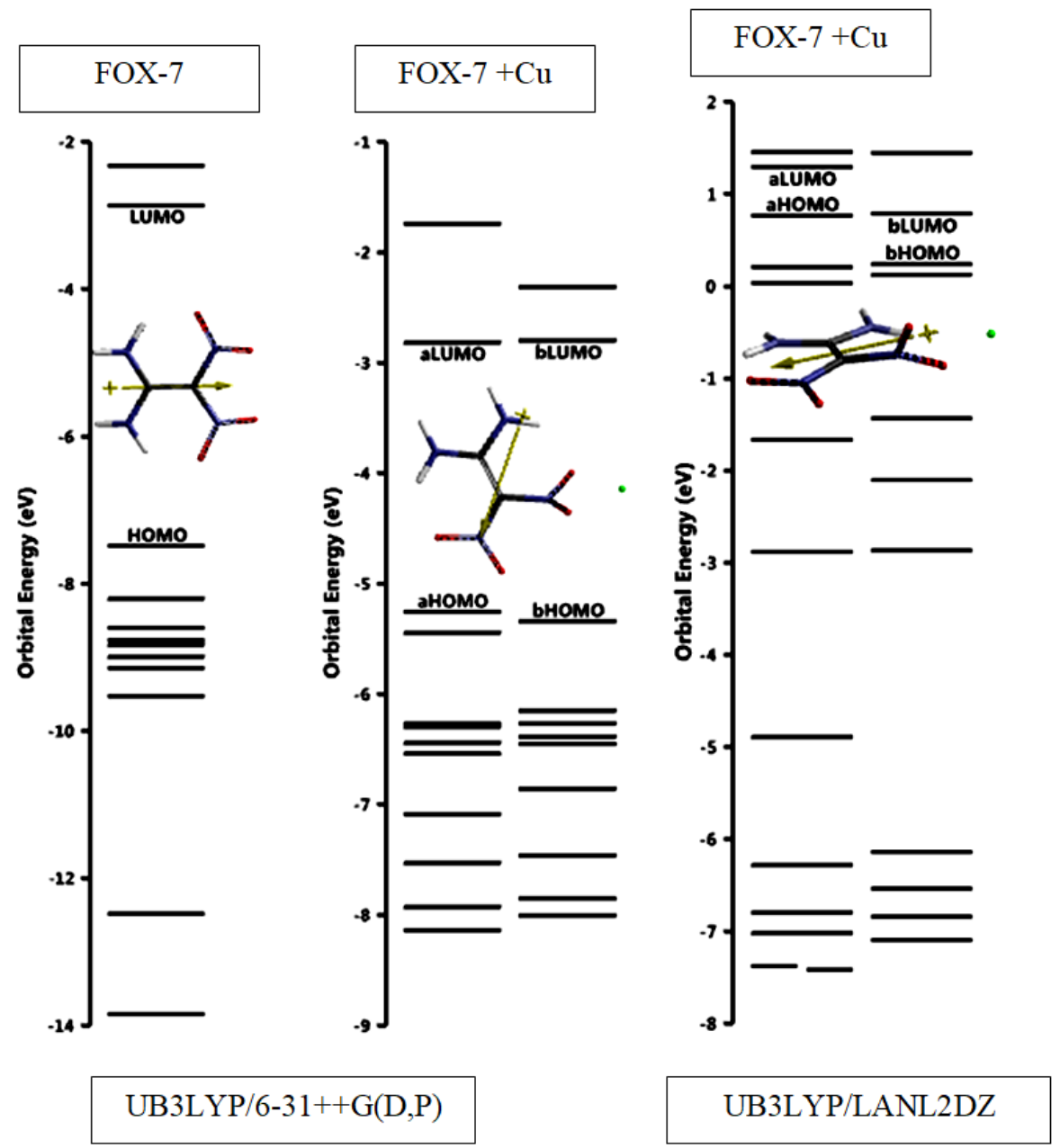

Figure 6. Some of the molecular orbital energies of FOX-7 and the composite.

Figures 7 and 8 show the HOMO and LUMO patterns of FOX-7 and the composite (UB3LYP/6-31++G(D,P)), respectively. In the case of FOX-7 the frontier molecular orbitals exhibit some sort of $\pi$-symmetry. In the composite case, $\alpha$ - and $\beta$-HOMO exhibit different patterns. In each case some contribution from d-atomic orbitals of the copper atom is discernable. On the other hand, $\alpha$ - and $\beta$-LUMO show the same pattern. Note that they are (almost) degenerate (see Figure 6). 


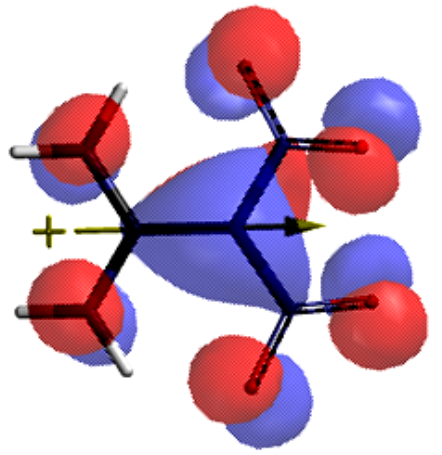

HOMO

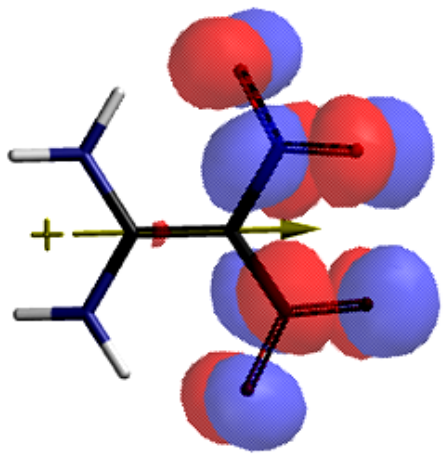

LUMO

Figure 7. The HOMO and LUMO patterns of FOX-7 (UB3LYP/6-31++G(D,P)).
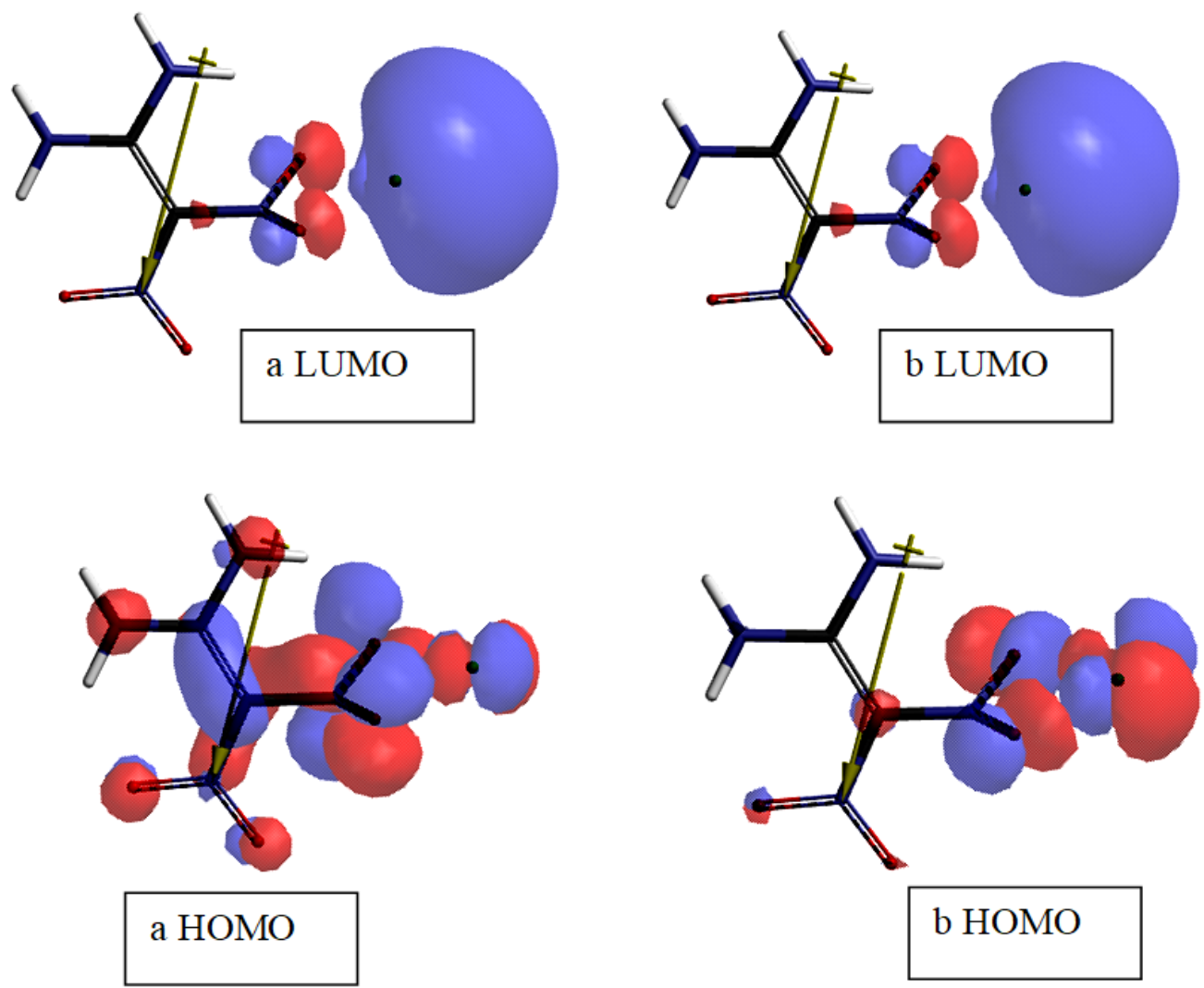

Figure 8. The HOMO and LUMO patterns of the composite (UB3LYP/6-31++G(d,p)). 
Figure 9 shows the local ionization maps of the structures considered. In a local ionization potential map conventionally red regions on the density surface indicate areas from which electron removal is relatively easy, meaning that they are subject to electrophilic attack.
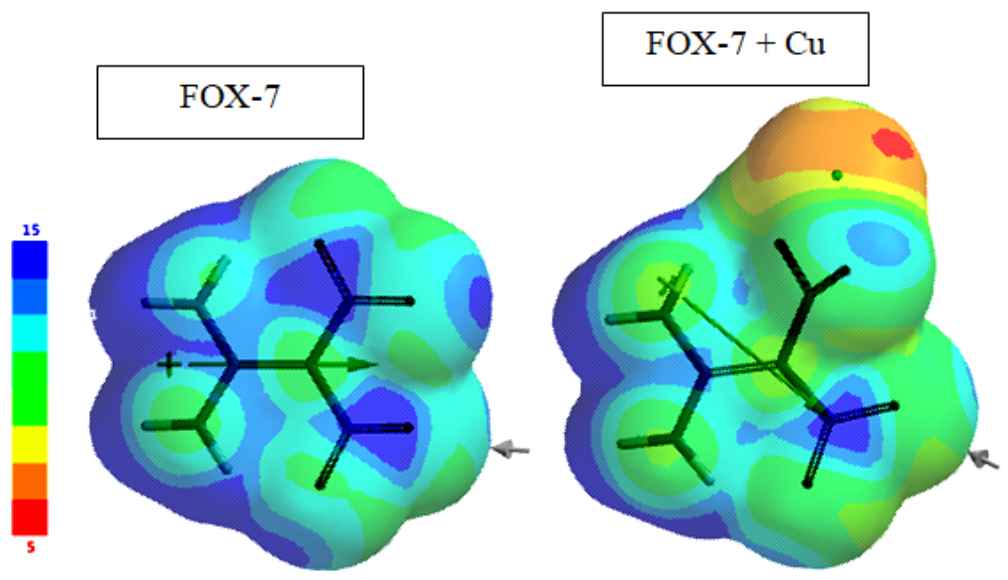

Figure 9. The local ionization maps of the structures considered (UB3LYP/6$31++\mathrm{G}(\mathrm{d}, \mathrm{p}))$.

Comparison of FOX-7 and the composite local ionization maps reveals that the electron population donated by the copper atom is widely distributed over the organic component of the composite. Therefore, blue/bluish regions of FOX-7 turn into greenish.

Figure 10 shows the spin density map of the composite which indicates the distribution of the unpaired electron over the system.

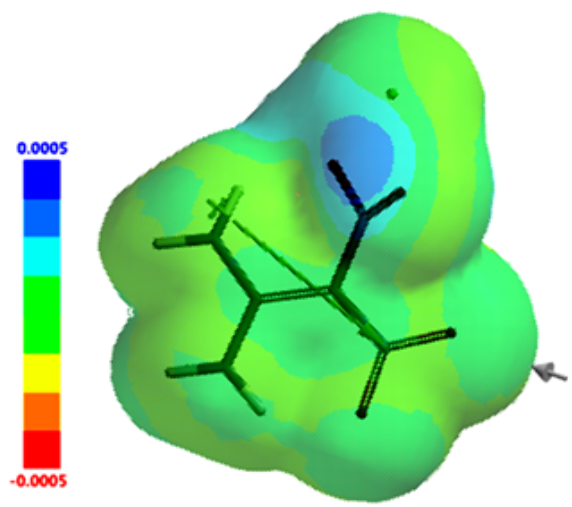

Figure 10. Spin density map of the composite (UB3LYP/6-31++G(d,p)). 


\section{Conclusion}

The effect of copper atom on FOX-7 has been investigated within the constraints of DFT. Two different basis sets were employed using the UB3LYP functional. Both of the basis sets predicted the similar geometries. The FOX-7 structure/bonding remained intact in the composite but some conformational changes occurred in the $\mathrm{C}-\mathrm{NO}_{2}$ bonds in such a way that the HOMO-LUMO energy gap decreased compared to FOX-7 case. This outcome is not only due to the indicated conformational changes but also because of the copper atom which donates some electron population to the organic component. All those changes occurring in the composite with respect to FOX-7 should affect ballistic properties as well, such as the impact sensitivity.

\section{References}

[1] N. Latypov, J. Bergman, A. Langlet, U. Wellmar and U. Bemm, Synthesis and reactions of 1,1-diamino-2,2-dinitroethylene, Tetrahedron 54 (1998), 11525-11536. https://doi.org/10.1016/S0040-4020(98)00673-5

[2] H. Ostmark, A. Langlet, H. Berman, N. Wingborg, U. Wellmar and U. Bemm, FOX-7 A new explosive with low sensitivity and high performance, 11th Int. Symp. Detonation, Snow Mass, Colorado, August 31 - September 4, 1998.

[3] S. Karlsson, H. Ostmark, C. Eldsater, T. Carlsson, H. Bergman, S. Wallin and A. Pettersson, Detonation and sensitivity properties of FOX-7 and formulations containing FOX-7, 12th Int. Symp. Detonation, San Diego, California, August 11-16, 2002.

[4] B. Janzon, H. Bergman, C. Eldsater, C. Lamnevik and H. Ostmark, FOX-7 - A novel, high performance, low vulnerability high explosive for warhead applications, 20th Int. Symp. Ballistics, Orlando, Florida, September 23-27, 2002.

[5] Y.N. Matyushin, G.T. Afanas'ev, V.P. Lebedev, M.N. Mahov and V.I. Pepekin, TATB and FOX-7: Thermochemistry, performance, detonability, sensitivity, 34th Int. Annu. Conf. ICT, Karlsruhe, Germany, June 24-27, 2003.

[6] S. Cudziło and W. Kicinski, Synthesis and properties of DADNE (in Polish), Biuletyn WAT 53(2-3) (2004), 183-204.

[7] A.J. Bellamy, N.V. Latypov and P. Goede, Studies on the nitration of new potential precursors for FOX-7, New Trends Res. Energ. Mater., Proc. Semin., 7th, Pardubice, Czech Republic, April 20-22, 2004. 
[8] Z. Chyłek, S. Cudziło, J. Błądek and S. Pietrzyk, Optimization of 1,1-diamino-2,2dinitroethene synthesis (in Polish), Biuletyn WAT 54(5-6) (2005), 19-16.

[9] S. Cudziło, Z. Chyłek and R. Diduszko, Crystallization and characterization of 1,1diamino-2,2-dinitroethene (DADNE) (in Polish), Biuletyn WAT 54(5-6) (2005), 5-18.

[10] S. Cudziło, Z. Chyłek and R. Diduszko, Crystallization and characterization of 1,1diamino-2,2-dinitroethene (DADNE), 36th Int. Annu. Conf. ICT, Karlsruhe, Germany, June 28-July 1, 2005.

[11] S. Cudziło and Z. Chyłek, 1,1-Diamino-2,2-dinitroethene (DADNE), a new high energetic and low sensitive explosive (in Polish), Wiadomości Chemiczne 60(11-12) (2006), 763791.

[12] W.A. Trzciński, S. Cudziło, Z. Chyłek and L. Szymańczyk, Investigation of sensitivity and detonation properties of FOX-7, 37th Int. Annu. Conf. ICT, Karlsruhe, Germany, June 27-30, 2006.

[13] M. Anniyappan, M.B. Talawar, G.M. Gore, S. Venugopalan and B.R. Ganghe, Synthesis, characterization and thermolysis of 1,1-diamino-2,2-dinitroethylene (FOX-7) and its salts, J. Hazard. Mater. B137 (2006), 812-819. https://doi.org/10.1016/j.jhazmat.2006.03.034

[14] W.A. Trzciński, S. Cudziło, Z. Chyłek and L. Szymańczyk, Determination of the expansion isentrope for detonation products of FOX-7, 38th Int. Annu. Conf. ICT, Karlsruhe, Germany, June 26-29, 2007.

[15] W.A. Trzciński, S. Cudziło, Z. Chyłek and L. Szymańczyk, Detonation properties of 1,1diamino-2,2-dinitroethene (DADNE), J. Hazard. Mater. 157 (2008), 605-612. https://doi.org/10.1016/j.jhazmat.2008.01.026

[16] W.A. Trzcıńsk1 and A. Belaada, 1,1-Diamino-2,2-dinitroethene (DADNE, FOX-7) Properties and formulations (a review), Central European Journal of Energetic Materials 13(2) (2016), 527-544. https://doi.org/10.22211/cejem/65000

[17] A.J. Bellamy, FOX-7 (1,1-Diamino-2,2-dinitroethene), in: Structure and Bonding (Klapötke, T.M., ed.), Springer, Berlin, Heidelberg 125 (2007), 1-33. https://doi.org/10.1007/430_2006_054

[18] A. Kretschmer, P. Gerber and A. Happ, Characterization of plastic bonded explosive charges containing FOX-7, 35th Int. Annu. Conf. ICT, Karlsruhe, Germany, June 29 July 2, 2004.

[19] L. Türker, Effect of magnesium on FOX-7 and its tautomers-A DFT treatment, Defence Technology 14(3) (2018), 179-187. https://doi.org/10.1016/j.dt.2017.11.009 
[20] L. Türker, Interaction of 1,1-diamino-2,2-dinitroethylene and gallium - DFT treatment, Earthline Journal of Chemical Sciences 2(2) (2019), 271-291.

https://doi.org/10.34198/ejcs.2219.271291

[21] L. Türker, Effect of aluminum on FOX-7 structure, Chinese Journal of Explosives and Propellants 42(3) (2019), 223-231.

https://doi.org/10.14077/j.issn.1007-7812.2019.03.002

[22] J.J.P. Stewart, Optimization of parameters for semiempirical methods I. Method, $J$. Comput. Chem. 10 (1989), 209-220. https://doi.org/10.1002/jcc.540100208

[23] J.J.P. Stewart, Optimization of parameters for semi empirical methods II. Application, $J$. Comput. Chem. 10 (1989), 221-264. https://doi.org/10.1002/jcc.540100209

[24] A.R. Leach, Molecular Modeling, Essex: Longman, 1997.

[25] P. Fletcher, Practical Methods of Optimization, New York: Wiley, 1990.

[26] W. Kohn and L. Sham, Self-consistent equations including exchange and correlation effects, J. Phys. Rev. 140 (1965), 1133-1138.

https://doi.org/10.1103/PhysRev.140.A1133

[27] R.G. Parr and W. Yang, Density Functional Theory of Atoms and Molecules, London: Oxford University Press, 1989.

[28] C.J. Cramer, Essentials of Computational Chemistry, Chichester, West Sussex: Wiley, 2004.

[29] A. Abkari, I. Chaabane and K. Guidara, DFT (B3LYP/LanL2DZ and B3LYP/6311G $+(\mathrm{d}, \mathrm{p})$ ) comparative vibrational spectroscopic analysis of organicinorganic compound bis(4-acetylanilinium) tetrachlorocuprate(II), Physica E: Lowdimensional Systems and Nanostructures 81 (2016), 136-144.

https://doi.org/10.1016/j.physe.2016.03.010

[30] A.D. Becke, Density-functional exchange-energy approximation with correct asymptotic behavior, Phys. Rev. A 38 (1988), 3098-3100. https://doi.org/10.1103/PhysRevA.38.3098

[31] S.H. Vosko, L. Wilk and M. Nusair, Accurate spin-dependent electron liquid correlation energies for local spin density calculations: a critical analysis, Can. J. Phys. 58 (1980), 1200-1211. https://doi.org/10.1139/p80-159

[32] C. Lee, W. Yang and R.G. Parr, Development of the Colle-Salvetti correlation-energy formula into a functional of the electron density, Phys. Rev. B 37 (1988), 785-789. https://doi.org/10.1103/PhysRevB.37.785

[33] SPARTAN 06, Wavefunction Inc., Irvine CA, USA, 2006. 
[34] R. Matyáš and J. Pachman, Primary Explosives, Berlin: Springer-Verlag, 2013. https://doi.org/10.1007/978-3-642-28436-6

[35] T.M. Klapötke, Chemistry of High-Energy Materials, Berlin: De Gruyter, 2011. https://doi.org/10.1515/9783110227840

[36] F.A. Cotton and G. Wilkinson, Advanced Inorganic Chemistry, New York: Interscience Pub.,1967.

[37] R.W. Lane and J. McDonald, Kinetics of the reaction between copper and aqueous ammonia, J. Am. Chem. Soc. 68(9) (1946), 1699-1704.

https://doi.org/10.1021/ja01213a005

[38] V. Anbu, K.A. Vijayalakshmi, R. Karunathan, A. David Stephen and P.V. Nidhin, Explosives properties of high energetic trinitrophenyl nitramide molecules: A DFT and AIM analysis, Arabian Journal of Chemistry 12(5) (2019), 621-632. https://doi.org/10.1016/j.arabjc.2016.09.023

[39] N.R. Badders, C. Wei, A.A. Aldeeb, W.J. Rogers and M.S. Mannan, Predicting the impact sensitivities of polynitro compounds using quantum chemical descriptors, Journal of Energetic Materials 24 (2006), 17-33. https://doi.org/10.1080/07370650500374326

[40] M.J.S. Dewar, The Molecular Orbital Theory of Organic Chemistry, New York: McGraw-Hill, 1969.

[41] I. Fleming, Frontier Orbitals and Organic Chemical Reactions, London: Wiley, 1976. 